Jurnal Sistim Informasi dan Teknologi
https://jsisfotek.org/index .php

\title{
Identifikasi Tingkat Kerusakan Peralatan Labor Teknik Komputer Jaringan Menggunakan Metode Decision Tree
}

\author{
Dinda Permata Sukma ${ }^{1 \bowtie}$, Sarjon Defit ${ }^{2}$, Gunadi Widi Nurcahyo ${ }^{3}$ \\ ${ }^{1}$ Independent Researcher \\ ${ }^{2,3}$ Universitas Putra Indonesia YPTK Padang \\ dindapermatasukma27@gmai1.com
}

\begin{abstract}
The computer laboratory is a place for practical learning for students, where computers have an important role in the smooth running of the practice. The use of computer labor at any time is very vulnerable to damage. If there is damage it will disrupt the teaching and learning process. Utilization of data mining in determining the level of damage is one of them. SMKN 1 Sintuk Toboh Gadang has 3 laboratories, TKJ (Network Computer Engineering), RPL (Software Engineering) and Technician labor. Application of the Decision Tree method in identifying damage to computer laboratory equipment, especially TKJ (Computer Network Engineering) labor. The data obtained in this study are computer equipment sourced from the computer laboratory of SMKN 1 Sintuk Toboh Gadang. Based on the analysis of the computer laboratory, there are 50 computer laboratory equipment. Furthermore, if the data is processed, several variables are needed to identify the level of damage to labor equipment including the name of the tool, number of tools, inspection, duration of use, and condition. The result of testing this method is to test whether the labor equipment can still be used or repaired. The purpose of this research is to help computer labor technicians to identify computer labor equipment that can still be used or repaired so that no damage occurs during practical learning hours. Furthermore, the best method in determining the level of damage to computer laboratory equipment is the Decision Tree Algorithm method. Decision Tree Algorithm is a predictive model using a decision tree structure and makes complex decisions simpler. The results of the research method show that the condition variable has the highest Gain value, namely 0.4734353 , then the variable length of use is obtained with a Gain value of 0.896038 . The factors that cause damage include the condition of the tool and the duration of use.
\end{abstract}

Keywords: Data Mining, Algorithm, Decision Tree, Identify, Damage.

\begin{abstract}
Abstrak
Laboratorium komputer merupakan tempat pembelajaran praktek bagi siswa, dimana komputer mempunyai peran penting dalam berjalan lancarnya praktek tersebut. Pemakaian labor komputer setiap saat sangat rentan terjadinya kerusakan. Jika terjadi kerusakan maka akan terganggunya proses belajar mengajar. Pemanfaatan data mining dalam menentukan tingkat kerusakan adalah salah satunya. SMKN 1 Sintuk Toboh Gadang mempunyai 3 labor, TKJ (Teknik Komputer Jaringan), RPL (Rekayasa Perangkat Lunak) dan labor Teknisi. Penerapan metode Decision Tree dalam mengidentifikasi kerusakan peralatan laboratorium komputer khususnya labor TKJ (Teknik Jaringan Komputer). Data yang di dapat dalam penelitian ini merupakan peralatan komputer yang bersumber pada laboratorium komputer SMKN 1 Sintuk Toboh Gadang. Berdasarkan analisis terhadap labor kompter tersebut terdapat 50 peralatan laboratorium komputer. Selanjutnya data tersebut di olah, beberapa variabel yang dibutuhkan untuk mengidentifikasi tingkat kerusakan peralatan labor diantaranya Nama alat, jumlah alat, pemeriksaan, lama pemakaian, dan kondisi. Hasil dari pengujian terhadap metode ini adalah di uji apakah peralatan labor masih bisa dipakai atau diperbaiki. Tujuan dari penelitian ini adalah membantu para teknisi labor komputer untuk identifikasi peralatan labor komputer yang masih bisa dipakai atau diperbaiki sehingga tidak terjadinya kerusakan disaat jam pembelajaran praktek berlangsung. Selanjutnya metode yang terbaik dalam menentukan tingkat kerusakan alat laboratorium komputer adalah metode Algoritma Decision Tree. Algoritma Decision Tree merupakan model prediksi menggunakan struktur pohon keputusan dan menghasilkan keputusan komplek menjadi lebih sederhana. Hasil dari metode penelitian menunjukkan didapat variabel kondisi memiliki nilai Gain tertinggi yaitu 0.4734353 selanjutnya didapat variabel lama pemakaian dengan nilai Gain 0.896038 . Faktor - faktor yang menyebabkan terjadinya kerusakan diantaranya kondisi alat dan lama pemakaian.
\end{abstract}

Kata kunci: Data Mining, Algoritma, Decision Tree, Identifikasi, Kerusakan

(C) 2021 JSisfotek

\section{Pendahuluan}

SMK (Sekolah Menengah Kejuruan) Negeri Sintuk Toboh Gadang adalah salah satu sekolah kejuruan yang selalu berusaha memberikan dan menghasilkan kualitas lulusan yang sangat berkompeten di bidang peminatannya, sehingga hasilnya dapat bermanfaat dan berpartisipasi di dunia kerja dengan kualitas yang maksimal. Sebagai salah satu sekolah yang sebelumnya adalah sekolah rintisan berbasis internasional. Sekolah ini dilengkapi dengan berbagai fasilitas pendidikan dan para pendidik yang cukup berkualitas di bidangnya.Sekolah ini memiliki banyak keunggulan dibanding dengan sekolah kejuruan lain yang ada di Kota pariaman bahkan di seluruh sekolah kejuruan di

Diterima: 01-00-2021 | Revisi: 01-10-2021 | Diterbitkan: 31-12-2021 | doi: 10.37034/jsisfotek.v3i4.78 
Padang Pariaman. Berbagai prestasi yang diraih oleh 93,103\% menggunakan 163 data latih dan 29 data uji siswa dan pengajar dari sekolah ini membuktikan atau $85 \%$ data latih dan $15 \%$ data uji [8]. Amalia dkk bahwa sekolah ini memang pantas menjadi salah satu (2020) memperoleh proses dataset kinerja siswa sekolah tujuan bagi calon siswa dan merupakan salah menggunakan metode algoritma C4.5 untuk satu sekolah kejuruan favorit di Kota Pariaman. SMKN meningkatkan kinerja Data Mining, yaitu 1 Sintuk Toboh Gadang mempunyai 3 labor mengoptimalkan metode seleksi, memperoleh akurasi diantaranya labor TKJ (Teknik Komputer Jaringan), nilai 87\% [9]. Hasil penelitian yang dilakukan oleh labor RPL (Rekayasa Perangkat Lunak) dan labor Wiza \& Febriadi (2019) dalam pengolahan Data Teknisi. Labor komputer digunakan ketika proses Mining menggunakan metode klasifikasi dan algoritma pembelajaran praktek, penggunaan labor secara berkala C4.5 dapat memprediksi tingkat kelulusan siswa menyebabkan rentan terjadinya kerusakan. Untuk dengan dua kategori yaitu lulus dan tidak lulus [10]. mengantisipasi kerusakan peralatan labor ketika proses Metode Algoritma Decision Tree juga pernah belajar berlangsung maka para teknisi harus dilakukan oleh peneliti-peneliti sebelumnya yang dapat mengetahui peralatan labor yang masih bisa digunakan menudukung pengolahan data [11]-[17].

dan yang tidak bisa digunakan [1].

Data Mining adalah teknik analisis data berbasis pada aplikasi statistik yang bertujuan untuk mengekstrak informasi itu sebelumnya tidak dapat ditentukan dari jumlah big data. Data Mining adalah sistem informasi berbasis komputer yang ingin memindai data besar repositori, menghasilkan informasi, dan menemukan pengetahuan [2]. Algoritma Decision Tree merupakan algoritma yang umum digunakan untuk pengambilan keputusan. Decision Tree akan mencari solusi permasalahan dengan menjadikan kriteria sebagai node yang saling berhubungan membentuk seperti struktur pohon. Decision Tree adalah model prediksi terhadap suatu keputusan menggunakan struktur hirarki atau pohon. Setiap pohon memiliki cabang, cabang mewakili setiap atribut yang harus dipenuhi untuk menuju cabang selanjutnya hingga berakhir di daun atau tidak ada cabang lagi [3]. Algoritma C4.5 merupakan metode yang dapat digunakan untuk melakukan pembentukan pohon keputusan. Decision tree tersebut mampu menghasilkan keputusan yang kompleks menjadi lebih sederhana, sehingga pengambil keputusan akan lebih menginterpretasikan solusi dari permasalahan [4]. Kelebihan dari metode Decision Tree ini adalah dapat menghasilkan sebuah pohon keputusan yang mudah dipahami, lebih sederhan dan mempunyai nilai akurasi yang mudah diterima [5]. Tujuan dalam penelitian menggunakan metode ini untuk membantu teknisi labor dalam menangani peralatan yang rusak disaat proses belajar mengajar berlangsung [6].

Beberapa penelitian terdahulu tentang Algoritma Decision Tree. Dari hasil penelitian menunjukkan bahwa algoritma C4.5 mampu mengklasifikasi berapa lama penggunaan komputer dilihat dari variabel jenis kelamin, umur dan lainnya [6]. Penelitian yang dilakukan oleh Syah (2020) menunjukkan bahwa model Decision Tree berhasil mengklasifikasikan hasil SKD menjadi 4 kelas berdasarkan nilai yang didapatkan peserta seleksi. Nilai performa model Decision Tree yang didapatkan bahwa Algoritma Decision Tree cocok sebagai model untuk klasifikasi pada penelitian ini [7]. Selanjutnya penelitian oleh Kurniawan dkk (2020) menghasilkan tingkat penerimaan yang dihasilkan dengan menggunakan confusion matrix adalah akurasi

\section{Metodologi Penelitian}

Pada kerangka penelitian ini akan dijelaskan tahapan tahapan yang akan dilakukan dalam menyelesaikan permasalahn yang ada. Adapun tahapan kerangka kerja dapat dilihat pada Gambar 1.

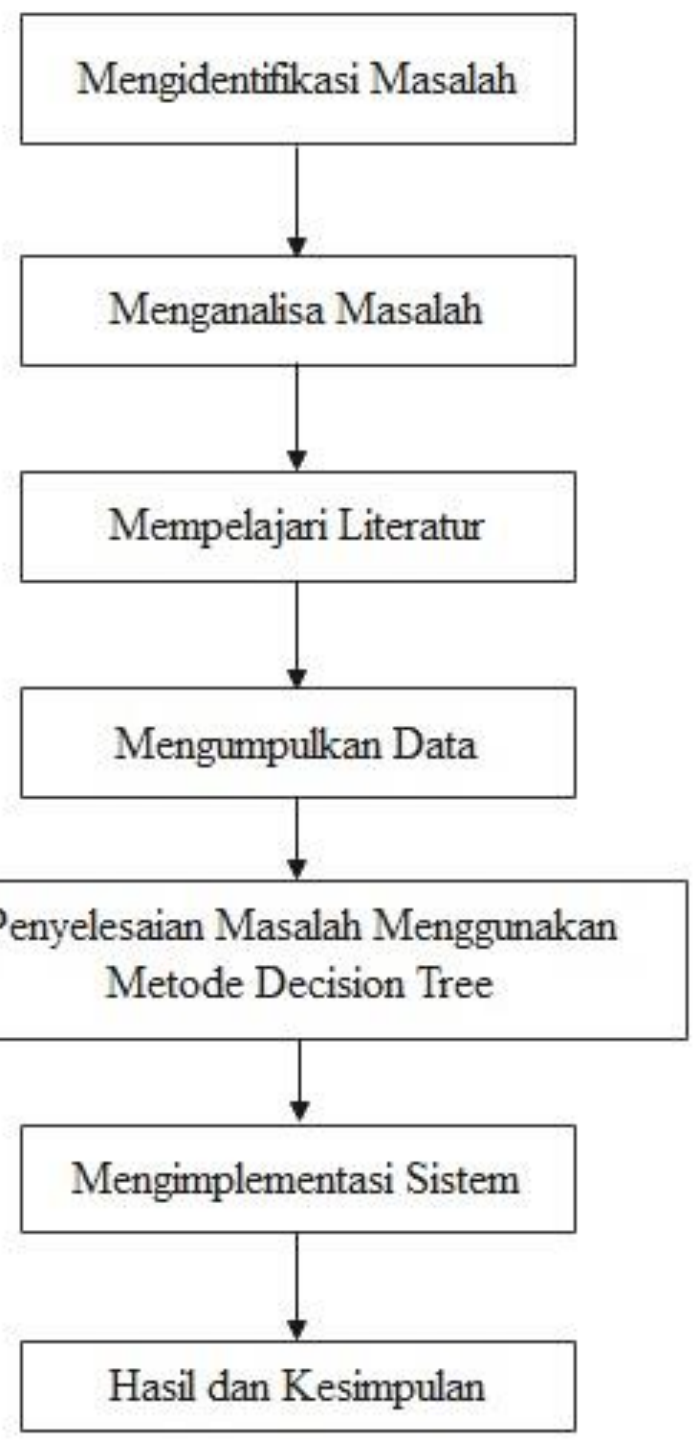

Gambar 1. Kerangka Kerja 


\subsection{Mengidentifikasi Masalah}

Tahapan ini merupakan tahapan paling awal dalam kerangka kerja penelitian. Data yang dibutuhkan untuk 3.2. Melakukan Perhitungan Menggunakan Metode mengidentifikasi tingkat kerusakan labor diantaranya Decision Tree

Nama Alat, Jumlah Alat, Pemeriksaan, Lama Pemakaian dan Kondisi

\subsection{Menganalisa Masalah}

Langkah analisis masalah adalah untuk dapat memahami masalah yang telah ditentukan ruang lingkup atau batasannya. Dengan menganalisa masalah yang telah ditentukan tersebut, maka diharapkan masalah dapat dipahami dengan baik

\subsection{Mempelajari Literatur}

Tahapan ini mempeljari literatur - literatur yang digunakan dalam. Literatur diambil dari berbagai sumber yaitu berupa artikel, jurnal ilmiah tentang simulasi Decision Tree, serta bahan bacaan lain yang mendukung.

\subsection{Mengumpulkan Data}

Tahapan mengumpulkan data yang dilakukan adalah dengan wawancara langsung dengan pihak sekolah dan observasi

2.5 Penyelesaian Masalah Menggunakan Metode Decision Tree

Penyelesaian masalah menggunakan metode Decision Tree diantaranya menentukan atribut, perhitungan nilai entropy dan nilai Gain, membentuk pohon keputusan dan Rule model

\subsection{Mengimplementasi Masalah}

Tahapan Mengimplementasi masalah dilakukan dari hasil analisa sebelumnya. Tujuan dari implementasi sistem ini dilakukan untuk melakukan perbandingan terhadap hasil yang diperoleh dengan analisa manual dengan sistem.

\subsection{Hasil dan Pembahasan}

Tahapan ini menentukan hasil perhitungan sehingga mengubah atribut yang komplek menjadi lebih sederhana dan mudah dipahami.

\section{Hasil dan Pembahasan}

Pada tahap ini akan dijelaskan bagan alir untuk memudahkan dalam menganalisa sistem

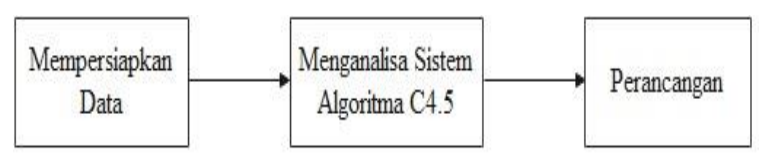

Gambar 2. Bagan Alir

\subsection{Mempersiapkan Data}

Tahap awal dalam menganalisa sistem yaitu mempersiapkan data. Data yang di olah bersumber dari labor TKJ (Teknik Komputer Jaringan) di SMKN 1 Sintuk Toboh Gadang.

Dalam algoritma C4.5 untuk membangun pohon keputusan hal pertama yang dilakukan yaitu memilih atribut sebagai akar. Secara umum algoritma Decision Tree C4.5 untuk membangun pohon keputusan adalah sebagai berikut:

a. Pilih Atribut sebagai root

b. Buat cabang untuk masing - masing nilai

c. Bagi atribut terpilih dalam cabang

d. Ulangi proses untuk masing - masing cabang sampai semua atribut terpilih pada cabang memiliki kelas yang sama.

Entropy Total

$$
\begin{aligned}
& \text { Entropy }(\text { Total })=\sum_{i=1}^{n}-P i \times \log _{2} P i \\
& \text { Entropy (Total) }\left(-\frac{39}{50} * \log ^{2}\left(\frac{39}{50}\right)\right) \\
&+\left(-\frac{11}{50} * \log ^{2}\left(\frac{11}{50}\right)\right) \\
& \text { Entropy (Total) }=0,760168
\end{aligned}
$$

Entropy Jumlah Alat(Banyak)

$$
\begin{gathered}
\text { Entropy (Banyak) }=\sum_{i=1}^{n}-P i \mathrm{x} \log _{2} P i \\
\text { Entropy (Banyak) } \\
=\left(-\frac{10}{12} * \log ^{2}\left(\frac{10}{12}\right)\right) \\
+\left(-\frac{2}{12} * \log ^{2}\left(\frac{2}{12}\right)\right) \\
\text { Entropy (Banyak) }=0,650022
\end{gathered}
$$

Entropy Jumlah Alat(Cukup)

$$
\begin{gathered}
\text { Entropy }(\text { Cukup })=\sum_{i=1}^{n}-P i \times \log _{2} P i \\
\text { Entropy (Cukup) } \\
=\left(-\frac{29}{38} * \log ^{2}\left(\frac{29}{38}\right)\right) \\
+\left(-\frac{9}{38} * \log ^{2}\left(\frac{9}{38}\right)\right)
\end{gathered}
$$

Entropy $($ Cukup $)=0,789749$

Entropy Periksa(Rutin)

$$
\text { Entropy }(\text { Rutin })=\sum_{i=1}^{n}-P i x \log _{2} P i
$$


Entropy (Rutin)

$$
\begin{aligned}
& =\left(-\frac{12}{21} * \log ^{2}\left(\frac{12}{21}\right)\right) \\
& +\left(-\frac{9}{21} * \log ^{2}\left(\frac{9}{21}\right)\right)
\end{aligned}
$$

Entropy $($ Rutin $)=0,985228$

Entropy Periksa(Tidak Rutin)

$$
\begin{array}{r}
\text { Entropy (Tidak Rutin) }=\sum_{i=1}^{n}-P i \times \log _{2} P i \\
\text { Entropy (Tidak Rutin) } \\
=\left(-\frac{27}{29} * \log ^{2}\left(\frac{27}{29}\right)\right) \\
+\left(-\frac{2}{29} * \log ^{2}\left(\frac{2}{29}\right)\right)
\end{array}
$$

Entropy $($ Tidak Rutin $)=0,362051$

Entropy Masa (1 Tahun)

$$
\begin{array}{r}
\text { Entropy (1 Tahun) }=\sum_{i=1}^{n}-P i \times \log _{2} P i \\
\text { Entropy (1 Tahun) } \\
=\left(-\frac{5}{9} * \log ^{2}\left(\frac{5}{9}\right)\right) \\
+\left(-\frac{4}{9} * \log ^{2}\left(\frac{4}{9}\right)\right) \\
\text { Entropy (1 Tahun) }=0,991076
\end{array}
$$

Entropy Masa (2 Tahun)

$$
\begin{aligned}
& \text { Entropy (2 Tahun) }=\sum_{i=1}^{n}-P i \times \log _{2} P i \\
& \begin{aligned}
& \text { Entropy (2 Tahun) } \\
&=\left(-\frac{8}{15} * \log ^{2}\left(\frac{8}{15}\right)\right) \\
&+\left(-\frac{7}{15} * \log ^{2}\left(\frac{7}{15}\right)\right)
\end{aligned}
\end{aligned}
$$

Entropy $(2$ Tahun $)=0,996792$

Entropy Masa (3 Tahun)

$$
\begin{aligned}
& \text { Entropy (3 Tahun) }=\sum_{i=1}^{n}-P i \times \log _{2} P i \\
& \text { Entropy (3 Tahun) } \\
& \begin{array}{l}
=\left(-\frac{26}{26} * \log ^{2}\left(\frac{2}{26}\right)\right) \\
+\left(-\frac{0}{26} * \log ^{2}\left(\frac{0}{26}\right)\right)
\end{array} \\
& \text { Entropy }(3 \text { Tahun })=0
\end{aligned}
$$

Entropy Kondisi (Baik)

$$
\begin{aligned}
\text { Entropy (Baik) } & =\sum_{i=1}^{n}-P i \times \log _{2} P i \\
\text { Entropy (Baik) } & =\left(-\frac{5}{16} * \log ^{2}\left(\frac{5}{16}\right)\right) \\
& +\left(-\frac{11}{16} * \log ^{2}\left(\frac{11}{16}\right)\right)
\end{aligned}
$$

$$
\text { Entropy }(\text { Baik })=0,896038
$$

Entropy Kondisi (Tidak Baik)

$$
\text { Entropy (Tidak Baik) }=\sum_{i=1}^{n}-P i \times \log _{2} P i
$$$$
\text { Entropy (Tidak Baik) }
$$

$$
\begin{aligned}
& =\left(-\frac{34}{34} * \log ^{2}\left(\frac{34}{34}\right)\right) \\
& +\left(-\frac{0}{34} * \log ^{2}\left(\frac{0}{34}\right)\right)
\end{aligned}
$$

Entropy $($ Tidak Baik $)=0$

Perhitungan Nilai Gain Node 1

Gain Jumlah Alat

Gain(Jumlah Alat)

Gain (Jumlah Alat)

$$
\begin{aligned}
& =\text { Entropy }(\text { Total }) \\
& -\sum_{i=1}^{n}-\left|\frac{S i}{S}\right| \times \text { Entropy }(\mathrm{s}
\end{aligned}
$$

$$
\begin{aligned}
& =0,760168-\left(\frac{12}{50} * 0,650022\right) \\
& +\left(\frac{38}{50} * 0,789749\right)=0,003953
\end{aligned}
$$

Gain Pemeriksaan

Gain(Pemeriksaan)

Gain (Pemeriksaan)

$$
\begin{aligned}
& =\text { Entropy }(\text { Total }) \\
& -\sum_{i=1}^{n}-\left|\frac{S i}{S}\right| \mathrm{x} \text { Entropy(s) }
\end{aligned}
$$

$$
\begin{aligned}
& =0,760168-\left(\frac{21}{50} * 0,985228\right) \\
& +\left(\frac{29}{50} * 0,362051\right)=0,136382
\end{aligned}
$$

Gain Lama Pemakaian

Gain(Jumlah Alat)

$$
\begin{aligned}
& =\text { Entropy (Total) } \\
& -\sum_{i=1}^{n}-\left|\frac{S i}{S}\right| \mathrm{x} \text { Entropy (s) }
\end{aligned}
$$

Gain (Lama Pemakaian)

$$
\begin{aligned}
& =0,760168-\left(\frac{9}{50} * 0,991076\right) \\
& +\left(\frac{15}{50} * 0,996792\right)+\left(\frac{26}{50} * 0\right) \\
& =0,282736
\end{aligned}
$$

Gain Kondisi

$$
\begin{aligned}
& \text { Gain }(\text { Kondisi })=\text { Entropy }(\text { Total }) \\
& \qquad \begin{aligned}
& \text { Gain }(\text { Kondisi }) \\
&= 0,760168-\left(\frac{16}{50} * 0,896038\right) \\
&+\left(\frac{34}{50} * 0\right)=0,47343
\end{aligned}
\end{aligned}
$$

Dari hasil perhitungan didapatkan pohon keputusan dengan variabel kondisi memiliki nilai Gain tertinggi, yaitu 0,47343 . Hasil perhitungan Node 1 disajikan pada Tabel 1. 
Tabel 1. Perhitungan Node 1

\begin{tabular}{lrrrcc}
\hline & $\mathrm{Jml}(\mathrm{S})$ & $\mathrm{A}(\mathrm{si})$ & $\mathrm{B}(\mathrm{si})$ & Entropy & Gain \\
\hline Jumlah & & & & & 0,0039 \\
Banyak & 50 & 39 & 11 & 0,7601 & \\
Cukup & 12 & 10 & 2 & 0,6501 & \\
\hline Periksa & & & & & 0,1364 \\
Rutin & 38 & 29 & 9 & 0,78970 & \\
Tidak & 21 & 12 & 9 & 0,98522 & \\
\hline Masa & & & & & 0,2827 \\
1 Th & 29 & 27 & 2 & 0,36205 & \\
2 Th & 9 & 5 & 4 & 0,99100 & \\
3 Th & 15 & 8 & 7 & 0,99670 & \\
\hline Kondisi & & & & & 0,4734 \\
Baik & 16 & 5 & 11 & 0,99670 & \\
Tidak & 34 & 34 & 0 & 0,89600 & \\
\hline
\end{tabular}

Selanjutnya dilakukan pengolaha untuk Node 2 yang hasilnya disajikan pada Tabel 2.

Tabel 2. Perhitungan Node 2

\begin{tabular}{lrrrcc}
\hline & $\mathrm{Jml}(\mathrm{S})$ & $\mathrm{A}(\mathrm{si})$ & $\mathrm{B}(\mathrm{si})$ & Entropy & Gain \\
\hline Jumlah & & & & & 0,0732 \\
Banyak & 2 & 0 & 2 & 0,0000 & \\
Cukup & 14 & 5 & 9 & 0,9402 & \\
\hline Periksa & & & & & 0,2585 \\
Rutin & 10 & 1 & 4 & 0,4689 & \\
Tidak & 6 & 4 & 2 & 0,9182 & \\
\hline Masa & & & & & 0,9402 \\
1 Th & 4 & 0 & 4 & 0 & \\
2 Th & 7 & 0 & 7 & 0 & \\
3 Th & 5 & 5 & 0 & 0 & \\
\hline
\end{tabular}

Dari hasil nilai entropy Node 2 telah didapatkan variabel jumlah alat memiliki nilai gain tertinggi.

\subsection{Pohon Keputusan (Decision Tree)}

Setelah pencarian nilai entropy dan gain didapat maka tahap selanjutnya adalah membuat pohon keputusan untuk menentukan hasil akhir dalam bentuk akar yang lebih sederhana. Berikut pohon keputusan dapat dilihat pada Gambar 3.

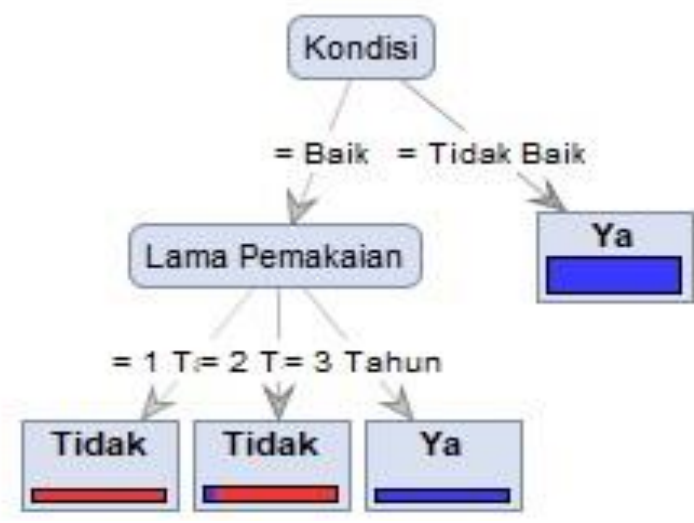

Gambar 3. Pohon Keputusan

\section{Kesimpulan}

Berdasarkan hasil yang didapatkan dengan menerapkan metode Decision Tree sangat membantu para teknisi dalam mengetahui identifikasi tingkat kerusakan peralatan labor Teknik Jaringan Komputer, sehingga tidak terjadinya kerusakan pada saat proses belajar mengajar belrlansung. Adapun faktor - faktor yang menyebabkan kerusakan peralatan labor dapat di lihat dari variabel kondisi dan berapa lama pemakaian.

\section{Daftar Rujukan}

[1] Pesah, S. W (2021), Analisis Lama Penggunaan Komputer Pada Universitas ABC Dengan Metode Algoritma C4.5, 7 (1). https://doi.org/10.46808/informa.v7i1.197

[2] Syah, R. D. (2020). Metode Decision Tree Untuk Klasifikasi Hasil Seleksi Kompetensi Dasar Pada Cpns 2019 Di Arsip Nasional Republik Indonesia. Jurnal Ilmiah Informatika Komputer, 25(2), 107-114. doi:10.35760/ik.2020.v25i2.2750

[3] Kurniawan, D., Anggrawan, A., \& Hairani, H. (2020). Graduation Prediction System On Students Using C4.5 Algorithm. MATRIK : Jurnal Manajemen, Teknik Informatika Dan Rekayasa Komputer, 19(2), 358-365. doi:10.30812/matrik.v19i2.685

[4] Aamalia, H., Yunita, Y., Puspita, A., \& Lestari, A. (2020). Student Performance Analysis Using C4.5 Algorithm To Optimize Selection. Jurnal Pilar Nusa Mandiri, 16(2), 149-154. https://doi.org/10.33480/pilar.v16i2.1348

[5] Wiza, F., \& Febriadi, B. (2019). Classification Analysis Using C4.5 Algorithm To Predict The Level of Graduation of Nurul Falah Pekanbaru High School Students. IJISTECH (International Journal Of Information System \& Technology), 2(2), 43. doi:10.30645/ijistech.v2i2.21

[6] Pratama, T. G., Ridwan, A., \& Prihandono, A. (2021). Penerapan Algoritma C4.5 untuk Klasifikasi Kanker Serviks Tingkat Awal. Urecol Journal. Part E: Engineering, 1(1), 1-6. doi:10.53017/uje. 4

[7] Lumban Gaol, L. Y., Safii, M., \& Suhendro, D. (2021). Prediksi Kelulusan Mahasiswa Stikom Tunas Bangsa Prodi Sistem Informasi Dengan Menggunakan Algoritma C4.5. Brahmana: Jurnal Penerapan Kecerdasan Buatan, 2(2), 97-106. doi:10.30645/brahmana.v2i2.71

[8] Oscario, O., Jasmir, J., \& Novianto, Y. (2019). Penerapan Algoritma C4.5 Untuk Memprediksi Kecocokan Gaya Belajar Bagi Siswa Siswi Sekolah Dasar (Studi Kasus : SD Sariputra Jambi) Jurnal Processor, 14(2), 141. doi:10.33998/processor.2019.14.2.637

[9] Li, S., \& Tang, H. (2020). Classification of Building Damage Triggered by Earthquakes Using Decision Tree. Mathematical Problems in Engineering, 2020, 1-15. doi:10.1155/2020/2930515

[10] Gumilar, R. (2020), Penerapan Data Mining Menggunakan Algoritma C4.5 Dalam Mengukur Tingkat Kepuasan Pasien BPJS, 2, 376-385. http://dx.doi.org/10.30645/senaris.v2i0.185

[11] Wanti, S. (2020), Penerapan Algoritma C4.5 dalam Meningkatkan Kemampuan Bahasa Inggris Pada Mahasiswa, 13(2). https://doi.org/10.33322/petir.v13i2.1029

[12] Fitriani, E. (2020). Perbandingan Algoritma C4.5 Dan Naïve Bayes Untuk Menentukan Kelayakan Penerima Bantuan Program Keluarga Harapan. Sistemasi, 9(1), 103. doi:10.32520/stmsi.v9i1.596

[13] Ucha, P. A., Eka, I. \& Fitri, R. (2021). Implementasi Data Mining Untuk Prediski Penyakit Diabetes dengan Algoritma C4.5, 2(1). https://doi.org/10.30645/kesatria.v2i1.56O

[14] Satria, F., Zamhariri, Z., \& Syaripudin, M. A. (2020). Prediksi Ketepatan Waktu Lulus Mahasiswa Menggunakan Algoritma C4.5 Pada Fakultas Dakwah Dan Ilmu Komunikasi UIN Raden Intan Lampung. Jurnal Ilmiah Matrik, 22(1), 28-35. doi:10.33557/jurnalmatrik.v22i1.836

[15] Rahayu, S., Damanik, I. S., \& Fauzan, M. (2021). Analisis Kepuasan Masyarakat Terhadap Kualitas Pelayanan Pada 
Pengadilan Negeri Simalungun Menggunakan Metode Algoritma C4.5. Jurasik (Jurnal Riset Sistem Informasi Dan Teknik Informatika), 6(1), 89. doi:10.30645/jurasik.v6i1.273

[16] Rahayu, S., Damanik, I. S., \& Fauzan, M. (2021). Analisis Kepuasan Masyarakat Terhadap Kualitas Pelayanan Pada Pengadilan Negeri Simalungun Menggunakan Metode
Algoritma C4.5. Jurasik (Jurnal Riset Sistem Informasi Dan Teknik Informatika), 6(1), 89. doi:10.30645/jurasik.v6i1.273

[17] Paul, V. M. (2021). Penerapan Data Mining Menggunakan Algoritma C4.5 Dalam Menentukan Kelayakan Penerimaan Bantuan Bedah Rumah pada Desa Tiga Dolok, 1(5) https://doi.org/10.36418/jurnalsostech.v1i5.102 